\title{
REDESAIN BODY MOBIL MATARAM PROTO V5 DENGAN MEMPERTIMBANGKAN ASPEK AERODINAMIS
}

\author{
Aji Pranoto ${ }^{1 *}$, Septa $W^{2}, K$. Yudha Orienta ${ }^{3}$, Wisnu Y. Santika ${ }^{4}$. \\ 1,2,3,4) Jurusan Teknik Mesin, Fakultas Teknologi Industri, IST AKPRIND Yogyakarta \\ Corresponding Author: aji_pranoto@akprind.ac.id; kyudhaorienta@gmail.com
}

\begin{abstract}
The Energy Saving Car Contest (KMHE) is a contest organized by the Ministry of Education, Culture, Research Technology (Kemendikbud-Ristek). This is a contest among students to make a national level fuel efficient vehicle. The purpose of designing this design is to produce an energy-efficient car body design "Mataram Proto" and to produce a vehicle that has a good aerodynamic level. This design of the car body is designed elegantly but still has good aerodynamics and does not reduce the safety aspects of the driver. The process of making a car body design uses Autodesk Inventor and the process of aerodynamic analysis of the Mataram Proto car body uses Ansys Mechanical software. Aerodynamic testing was carried out at an air speed of $45 \mathrm{~km} / \mathrm{h}$ or $12.5 \mathrm{~m} / \mathrm{s}$. From the previous Mataram Proto body test results, the drag coefficient was 0.233 and the lift coefficient was 0.1887 and from the Mataram Proto V5 car body test, the drag coefficient was 0.47 and the lift coefficient was 9.95. From the results of this test, it shows that the previous Mataram Proto car body had a better aerodynamic level due to the difference in the input of different airspeed variables, where the air velocity on the previous Mataram Proto car body was 40 $(\mathrm{km} / \mathrm{h})$ and the air speed on the Mataram Proto V5 body. amounting to 45 ( $\mathrm{km} / \mathrm{hour}$ ).
\end{abstract}

Keywords: Design, Aerodynamics, Drag Coefficient, and Lift Coefficient.

\begin{abstract}
ABSTRAK
Kontes Mobil Hemat Energi (KMHE) adalah sebuah kontes yang diselenggarakan oleh Kementrian Pendidikan Kebudayaan Riset Teknologi (Kemendikbud-Ristek). Merupakan kontes di kalangan mahasiswa untuk membuat kendaraan yang irit bahan bakar tingkat nasional. Tujuan dilakukannya perancangan ini yaitu Menghasilkan desain bodi mobil hemat energi "Mataram Proto" dan Menghasilkan suatu Bodi kendaraan yang memiliki tingkat Aerodinamis baik. Perancangan ini bentuk bodi mobil didesain secara elegan namun tetap memiliki aerodinamis yang baik dan tidak mengurangi aspek keselamatan pengemudi. Proses pembuatan desain bodi mobil menggunakan Autodesk Inventor dan proses analisa aerodinamika bodi mobil Mataram Proto menggunakan software Ansys Mechanical. Pengujian aerodinamis dilakukan pada kecepatan udara $45 \mathrm{Km} / \mathrm{jam}$ atau $12.5 \mathrm{~m} / \mathrm{s}$. Hasil pengujian bodi mobil Mataram Proto sebelumnya di dapatkan hasil koefisien drag 0.233 dan koefisien lift 0.1887 dan dari pengujian bodi mobil Mataram Proto V5 ini didapatkan hasil koefisien drag 0.47 dan koefisien lift 0.995. Dari hasil pengujian ini menunjukan bahwa bodi mobil Mataram Proto sebelumnya memiliki tingkat aerodinamis yang lebih baik dikarenakan perbedaan input variabel kecepatan udara yang berbeda, dimana kecepatan udara pada bodi mobil Mataram Proto sebelumnya sebesar 40 ( $\mathrm{km} / \mathrm{jam})$ dan kecepatan udara pada bodi Mataram Proto V5 sebesar 45 (km/jam).
\end{abstract}

Kata Kunci: Rancangan, Aerodinamika, Koefisien Drag, dan Koefisien Lift 


\section{PENDAHULUAN}

Kontes Mobil Hemat Energi (KMHE) adalah sebuah kontes yang diselenggarakan diselenggarakan oleh Kementrian Pendidikan Kebudayaan Riset Teknologi (KemendikbudRistek). KMHE merupakan kontes di kalangan mahasiswa untuk membuat kendaraan yang irit bahan bakar tingkat nasional. Peserta dituntut untuk mendesain dan membuat kendaraan masa depan yang hemat energi.

Kendaraan prototype adalah kendaraan yang dirancang beroda 3 yang merupakan kendaraan masa depan yang memiliki aerodinamika yang baik, sehingga ditargetkan memiliki efisiensi tinggi. Kendaraan Prototype ini tidak seperti kendaraan pada umumnya, kendaraan ini dikendarai oleh 1 orang dan lebih mengutamakan segi aerodinamis sehingga harus mengurangi gaya gesek yang ada pada kendaraan.

Kendaraan yang memiliki bodi yang Aerodinamis seperti kendaraan mataram proto IST AKPRIND memiliki banyak hal yang mempengaruhinya. Menurut (Andre Budhi Hendrawan, dan Togar Daniel H) salah satu besaran hambatan atau resistensi dari suatu obyek dalam hal ini adalah udara yang melaluinya yang diukur dengan besaran yang dinyatakan dengan nilai Coefficent Of drag (Cd). Hambatan udara kendaraan (D) diungkapkan dengan persamaan $D=0,5 \cdot \rho \cdot C d \cdot V^{2} A$. Besarnya gaya hambat aerodinamika dapat diformulasikan :

$$
\text { koefisien drag : } \mathrm{Cd}=\frac{D}{0,5 \cdot \rho \cdot C d \cdot V^{2} A}
$$

Dimana :

D : Hambatan Udara (N)

CD : Koefisien hambatan udara

$\rho \quad$ : Massa jenis udara $\left(1,12 \mathrm{Kg} / \mathrm{m}^{3}\right)$

$\mathrm{v}: \operatorname{Kecepatan}(\mathrm{m} / \mathrm{s})$

A : Luas penampang tegak lurus $\left(\mathrm{m}^{2}\right)$

(Clancy, 1975)

Konsumsi bahan bakar pada kendaraan banyak dipengaruhi oleh bentuk aerodinamis dan meminimalkan tahanan udara (drag). Gaya hambatan (drag) merupakan interpretasi dari besar hambatan udara yang diterima oleh suatu benda saat bergerak melalui udara. Gaya drag tekanan atau sering disebut drag tekanan adalah bagian dari drag yang langsung disebabkan oleh tekanan, P, pada sebuah benda. Drag ini sering disebut sebagai drag bentuk 
karena ketergantungan yang sangat kuat pada bentuk benda. Drag tekanan adalah fungsi dari besarnya tekanan dan orientasi arah elemen permukaan dimana gaya tekanan tersebut bekerja. (Muh Juhri;2018)

\section{METODE}

1. Pembuatan Desain

Pembuatan desain menggunakan program Autodesk Inventor 2015. Dalam membuat desain harus sesuai dengan regulasi yang ditetapkan oleh panitia KMHE agar mobil dapat lolos secruiting test dan masuk tahap selanjutnya. Selanjutnya dilakukan simulasi dengan metode computational fluid dynamics (CFD) pada Program Ansys. Desain rancangan Mataram Proto V5 ada beberapa langkah. Langkah pertama dalam analisis aerodinamika pada $C F D$ adalah membangun model dimana model dibangun menggunakan perangkat lunak dengan merujuk pada model kendaraan yang sesungguhnya. Langkah kedua adalah daerah komputasi (computational domain) analisis CFD aerodinamika. Dimensi computational domain dinyatakan dalam L, dimana $\mathrm{L}$ adalah panjang dari kendaraan yang akan disimulasikan. Langkah ketiga adalah meshing dimana model kemudian dimesh pada mesh builder. Meshing menggunakan dua metode. mesh otomatis dengan bentuk tri element dengan elemen paling kecil $1 \mathrm{~mm}$. Meshing menggunakan fitur inflation untuk membentuk lapisan batas pada permukaan bodi dan didapatkan bentuk mesh yang terbaik dan memudahkan perhitungan (literasi). Kondisi batas yang digunakan pada daerah perhitungan dibagi atas atas, bawah, samping, simetri, depan dan belakang. Pada batas depan dimasukkan kecepatan seragam dengan besar yang divariasikan.. Desain rancangan Mataram Proto V5 dapat dilihat pada Gambar 1.

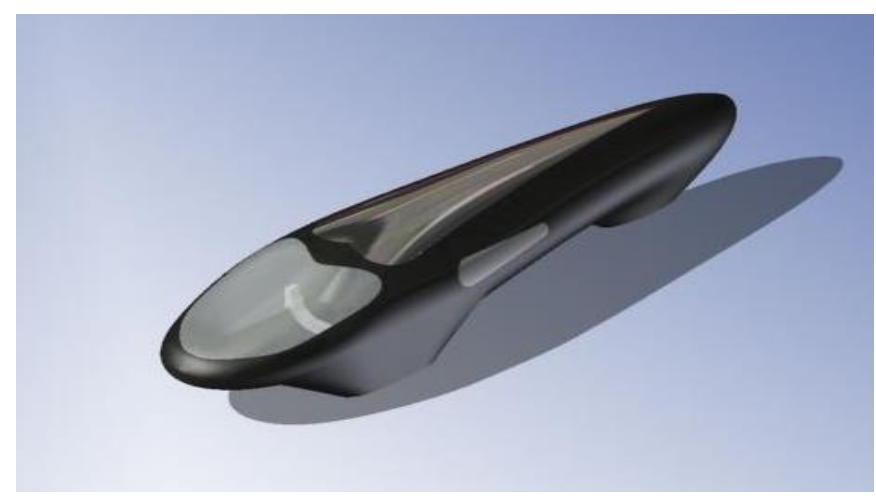

Gambar 1. Mataram Proto V5

2. Import Geometri

Langkah selanjutnya adalah melakukan import geometri pada Ansys dengan hasil seperti pada Gambar 2. 


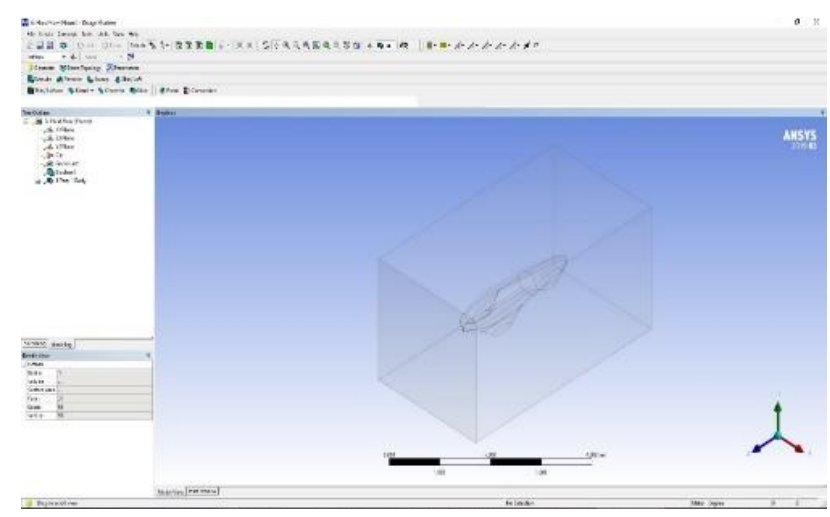

Gambar 2. Import Mataram Proto V5

3. Proses Meshing

Mesh ini dapat membuat meshing untuk berbagai macam bentuk, termasuk bentukbentuk yang rumit dan tidak beraturan.

Hasil meshing pada Mataram Proto V5 dapat dilihat pada Gambar 3.

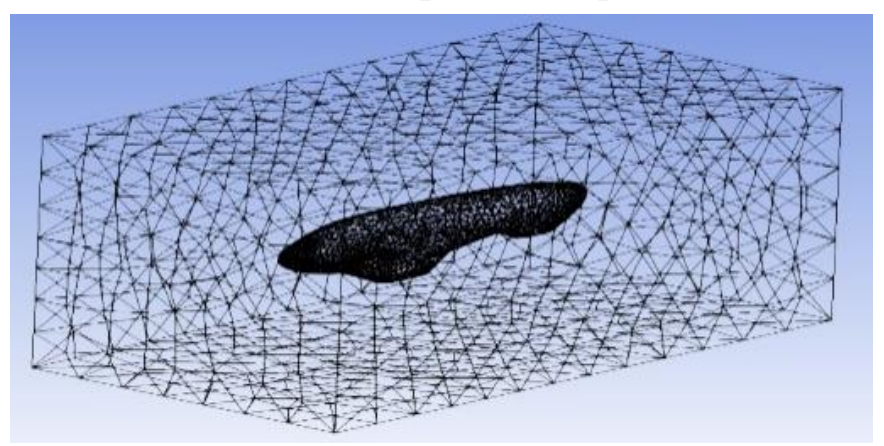

Gambar 3. Meshing Mataram Proto V5

\section{Setup Fluent}

Pada proses ini merupakan pengaturan variabel-variabel yang diperlukan dalam pengujian aerodinamis body mobil mataram proto V5, seperti dimensi, meshing, material, viscositas udara, arah udara yang mengarah ke body mobil, perhitungan velocity, tekanan, momen, densitas, koefisien drag, koefisien lift, dan residual udara. Variabel yang digunakan dalam setup fluent dapat dilihat pada Gambar 4.

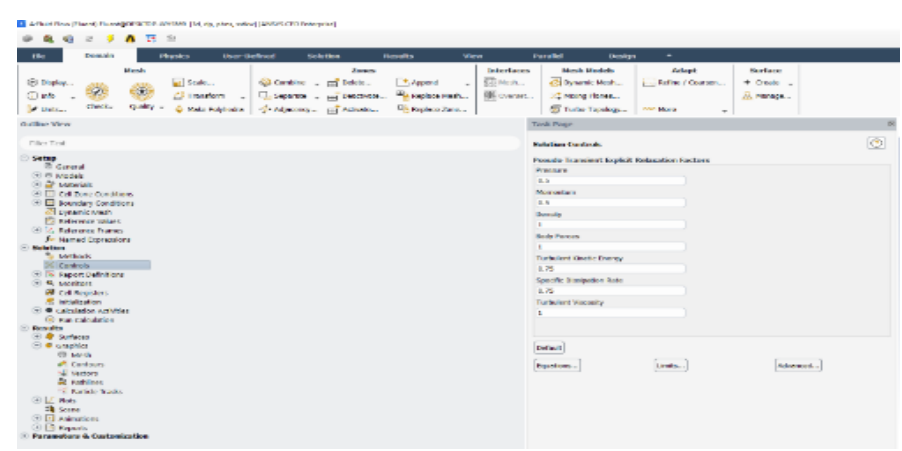

Gambar 4. Setup Fluent Mataram Proto V5 


\section{HASIL DAN PEMBAHASAN}

Pengujian aerodinamis dilakukan pada kecepatan udara $45 \mathrm{Km} / \mathrm{jam}$ atau $12.5 \mathrm{~m} / \mathrm{s}$. Dari hasil pengujian menggunakan software Ansys Mechanical didapatkan hasil koefisien drag 0.47 dan koefisien lift 0.995 . Berikut grafik dan table hubungan iteration dengan koefisien drag, koefisien lift, dan running time:

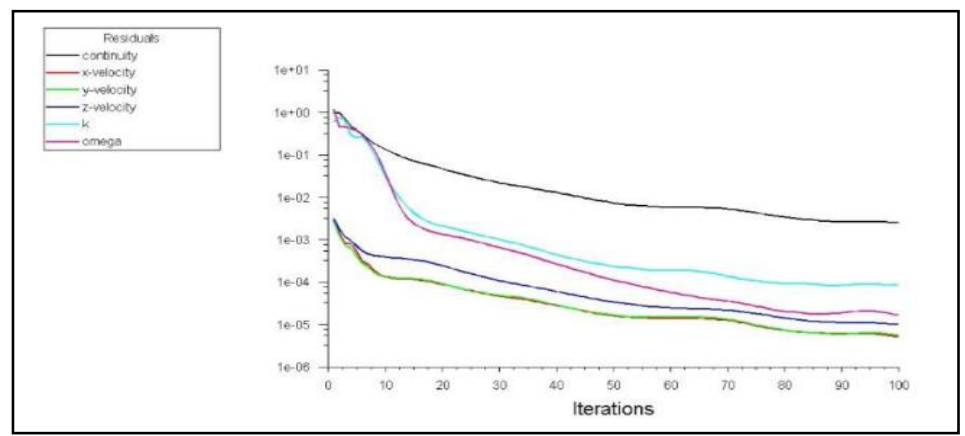

Gambar 5. Grafik Hubungan Iteration dengan Running Time

Dengan kriteria konvergensi 10-5, untuk mencapai konvergensi ada 100 jumlah iterasi dan membutuhkan waktu untuk running dari iterasi 95 - 100 membutuhkan waktu running 20 detik. Dengan hasil hubungan iteration dan running time dapat dilihat pada table 1.

Tabel 1 Hasil Hubungan Iterration dan Running Time

\begin{tabular}{|c|c|c|c|c|c|c|c|}
\hline Iterration & $\begin{array}{c}\text { Continuit } \\
y\end{array}$ & $x$-velocity & $y$-velocity & z-velocity & $K$ & Omega & $\begin{array}{c}\text { Time/Itera } \\
\text { tion }\end{array}$ \\
\hline 95 & $2,77 \mathrm{E}+01$ & $6,26 \mathrm{E}-02$ & $6,55 \mathrm{E}-02$ & $1,13 \mathrm{E}-01$ & $9,22 \mathrm{E}-01$ & $2,12 \mathrm{E}-01$ & $0: 00: 205$ \\
\hline 96 & $2,76 \mathrm{E}+01$ & $6,11 \mathrm{E}-02$ & $6,47 \mathrm{E}-02$ & $1,11 \mathrm{E}-01$ & $9,15 \mathrm{E}-01$ & $2,07 \mathrm{E}-01$ & $0: 00: 164$ \\
\hline 97 & $2,72 \mathrm{E}+01$ & $5,88 \mathrm{E}-02$ & $6,30 \mathrm{E}-02$ & $1,09 \mathrm{E}-01$ & $8,98 \mathrm{E}-01$ & $2,00 \mathrm{E}-01$ & $0: 00: 123$ \\
\hline 98 & $2,68 \mathrm{E}+01$ & $5,64 \mathrm{E}-02$ & $6,10 \mathrm{E}-02$ & $1,07 \mathrm{E}-01$ & $8,88 \mathrm{E}-01$ & $1,89 \mathrm{E}-01$ & $0: 00: 092$ \\
\hline 99 & $2,62 \mathrm{E}+01$ & $5,44 \mathrm{E}-02$ & $5,93 \mathrm{E}-02$ & $1,04 \mathrm{E}-01$ & $8,84 \mathrm{E}-01$ & $1,77 \mathrm{E}-01$ & $0: 00: 051$ \\
\hline 100 & $2,58 \mathrm{E}+01$ & $5,35 \mathrm{E}-02$ & $5,83 \mathrm{E}-02$ & $1,01 \mathrm{E}-01$ & $8,88 \mathrm{E}-01$ & $1,75 \mathrm{E}-01$ & $0: 00: 000$ \\
\hline
\end{tabular}

Tabel hasil hubungan iterration dan running time dibuat menjadi sebuah grafik hubungan antara koefisien drag dan koefisien lift terhadap iteration. Hasil grafik tersebut ditampilkan seperti grafik dibawah ini. 


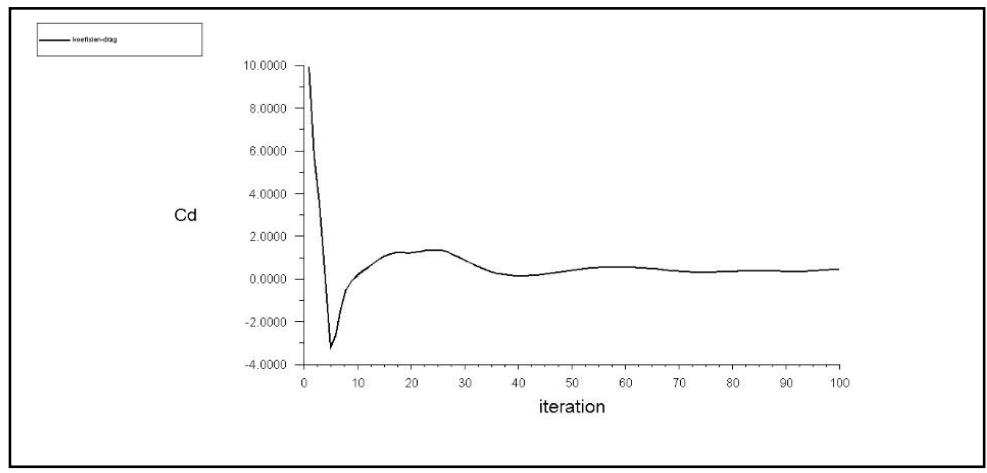

Gambar 6. Grafik Hubungan Iteration dengan Koefisien Drag

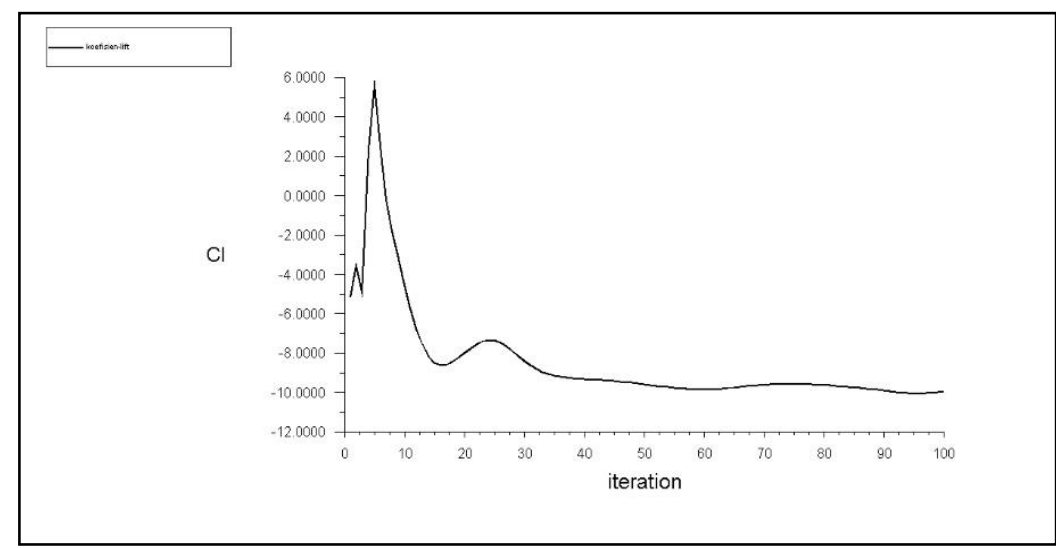

Gambar 7. Grafik Hubungan Iteration dengan Koefisien Lift

Hasil grafik diatas dapat dilihat pada grafik 2. bahwa koefisien drag yang terjadi pada body Kendaraan sebesar 0,47. Yang dimana semakin kecil nilai koefisien drag kendaraan maka semakin aerodinamis kendaraan tersebut. Dan pada grafik 3 dapat dilihat bahwa koefisien. lift yang terjadi pada body kendaraan sebesar 9,95. Yang dimana semakin kecil nilai koefiseisn lift kendaraan maka semakin kecil gaya angkat kendaraan tersebut.

Hasil simulasi dapat juga dilihat aliran udara disekitar kedua bodi kendaraan yang dapat dilihat pada Gambar 8.

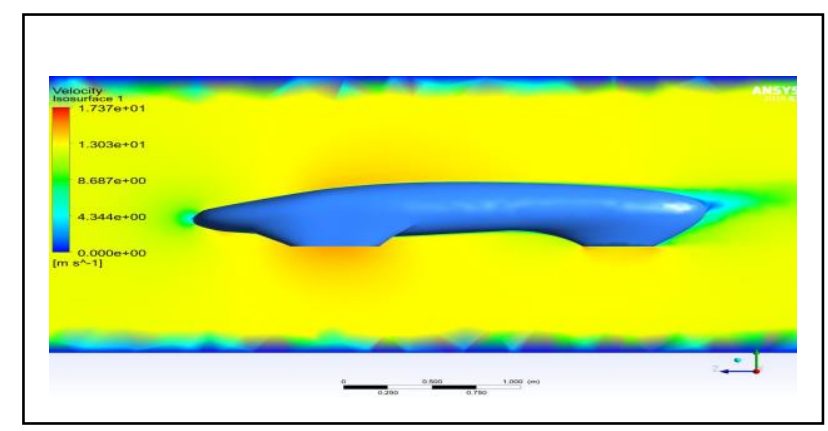

Gambar 8. Aliran udara disekitar bodi Mataram Proto 
Gambar 5 dapat dilihat bahwa bagian-bagian dari body kendaraan Mataram Proto yang dimana dalam kondisi tersebut sangat menghambat udara yang dibagi dengan beberapa warna. Warna merah menujukan bagian atau posisi yang 27 paling tinggi menghambat aliran udara yang mengalir didaerah tersebut. Sedangkan warna biru menunjukan daerah yang dialiri udara merupakan bagian yang paling sedikit mengalami hambatan udara

Dapat juga ditampilkan contour pressure disekitar bodi kendaraan yang ditunjukkan pada Gambar 9.

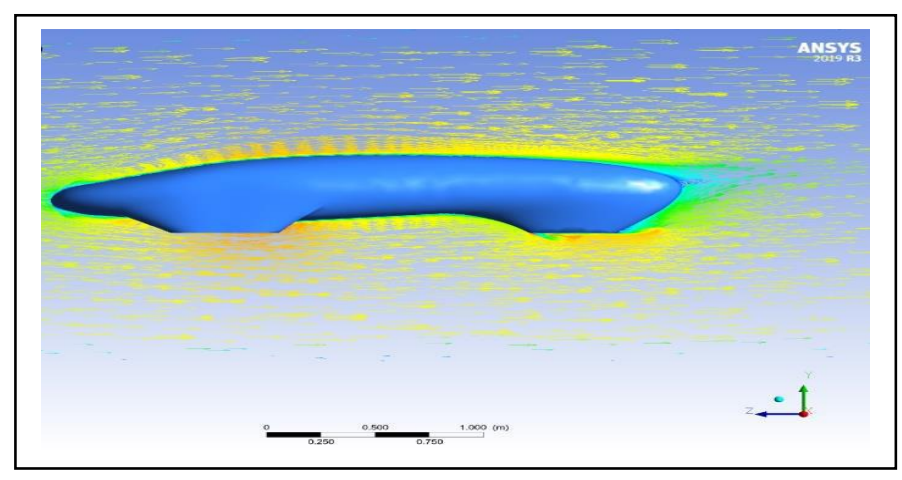

Gambar 9. Pressure bodi Mataram Proto V5

Gambar 6 dapat dilihat bahwa tekanan terbesar pada Mataram Proto V5 terdapat pada bagian depan kendaraan dan belakang kendaraan dibagian roda ditunjukkan dengan warna merah,

Selanjutnya adalah aliran streamline disekitar bodi kendaraan yang ditunjukkan Gambar 10.

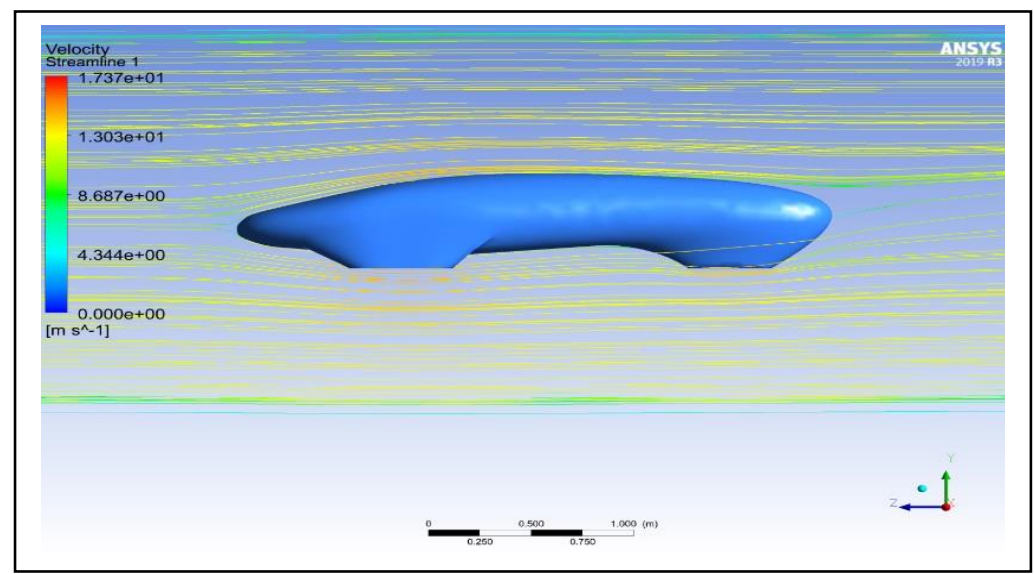

Gambar 10. Streamline bodi Mataram Proto V5 
Gambar 10 menunjukkan Streamline pada Mataram Proto V5 dapat dilihat bagian atas dan bawah aliran streamline nya lebih terhambat dan pada bagian depan terlihat alirannya lebih streamline.

\section{KESIMPULAN}

Pada perancangan bodi mobil Mataram Proto sebelumnya di dapatkan hasil koefisien drag 0.233 dan koefisien lift 0.1887 dan dari pengujian bodi mobil Mataram Proto V5 ini didapatkan hasil koefisien drag 0.47 dan koefisien lift 9.95. Dari hasil pengujian ini menunjukan bahwa bodi mobil Mataram Proto sebelumnya memiliki tingkat aerodinamis yang lebih baik dikarenakan perbedaan input variabel kecepatan udara yang berbeda, dimana kecepatan udara pada bodi mobil Mataram Proto sebelumnya sebesar $40(\mathrm{~km} / \mathrm{jam})$ dan kecepatan udara pada bodi Mataram Proto V5 sebesar 45 (km/jam).

\section{DAFTAR PUSTAKA}

Anderson Jr, John D.2001. "Fundamentals of Aerodynamics," 3rd Edition, McGraw-Hill Higher Education, Florida.

Andre Budhi Hendrawan, M.T , Nur Aidi Ariyanto, M.T., 2020, "Rancang Bangun Mesin CNC Router 3 AXIS Berbantu Perangkat Lunak Autodesk Inventor 2015", Journal Mechanical Engineering, Vol 9, No 2, hlm 31-37.

Muh Jufri, dkk, 2018, “Analisis Koefisien Aerodinamis Pada Mobil Hemat Energi Genetro Suryo Fakultas Teknik Universitas Muhammadiyah Malang” Jurnal Nasional Teknologi dan Rekayasa (SENTRA). No 04 2018, hlm 104-108

Munson, dkk., 2002 “Fundamentals of Fluid Mechanics,” Sixth Edition. New York.

Prihadnyana, Y., Gede Widayana, S. T., \& Dantes, K. R. (2017). “Analisis Aerodinamika Pada Permukaan Bodi Kendaraan Mobil Listrik Gaski (Ganesha Sakti) Dengan Perangkat Lunak Ansys 14.5." Jurnal Pendidikan Teknik Mesin Undiksha.

Togar Daniel H., 2018, "Simulasi aerodinamika pada mobil listrik NOGOGENI dengan menggunakan software ansys fluent." Tugas akhir Teknik mesin, Institut Teknologi Sepuluh Nopember Surabaya. 